\title{
Temperature variability in the Iberian Range since 1602 inferred from tree-ring records
}

\author{
Ernesto Tejedor ${ }^{1,2,3}$, Miguel Ángel Saz ${ }^{1,2}$, José María Cuadrat ${ }^{1,2}$, Jan Esper $^{3}$, and Martín de Luis ${ }^{1,2}$ \\ ${ }^{1}$ University of Zaragoza, 50009 Zaragoza, Spain \\ ${ }^{2}$ Environmental Sciences Institute of the University of Zaragoza, Zaragoza, Spain \\ ${ }^{3}$ Department of Geography, Johannes Gutenberg University, 55099 Mainz, Germany \\ Correspondence to: Ernesto Tejedor (etejedor@unizar.es)
}

Received: 18 January 2016 - Discussion started: 2 February 2016

Revised: 26 December 2016 - Accepted: 18 January 2017 - Published: 9 February 2017

\begin{abstract}
Tree rings are an important proxy to understand the natural drivers of climate variability in the Mediterranean Basin and hence to improve future climate scenarios in a vulnerable region. Here, we compile 316 tree-ring width series from 11 conifer sites in the western Iberian Range. We apply a new standardization method based on the trunk basal area instead of the tree cambial age to develop a regional chronology which preserves high- to low-frequency variability. A new reconstruction for the 1602-2012 period correlates at -0.78 with observational September temperatures with a cumulative mean of the 21 previous months over the 19452012 calibration period. The new IR2Tmax reconstruction is spatially representative for the Iberian Peninsula and captures the full range of past Iberian Range temperature variability. Reconstructed long-term temperature variations match reasonably well with solar irradiance changes since warm and cold phases correspond with high and low solar activity, respectively. In addition, some annual temperature downturns coincide with volcanic eruptions with a 3 -year lag.
\end{abstract}

\section{Introduction}

The Intergovernmental Panel on Climate Change (IPCC, 2013) highlighted a likely increase in average global temperatures in the coming decades, pointing particularly to the Mediterranean Basin, and therefore also the Iberian Peninsula (IP), as a region of substantial modeled temperature changes. The Mediterranean area is located in the transitional zone between tropical and extratropical climate systems, characterized by complex topography and high cli- matic variability (Hertig and Jacobeit, 2008). When taking into account these features, even relatively minor modifications of the general circulation, i.e., a shift in the location of sub-tropical high pressure cells, can lead to substantial changes in Mediterranean climate (Giorgi and Lionello, 2008), making the study area a potentially vulnerable region to anthropogenic climatic changes by anthropogenic forces, i.e., increasing concentrations of greenhouse gases (Lionello et al., 2006a).

Major recent efforts have been made in understanding trends in temperatures throughout the IP over the instrumental period (El Kenawy et al., 2012; Pena-Angulo et al., 2015; González-Hidalgo et al., 2015) and future climate change scenarios (Sánchez et al., 2004; López-Moreno et al., 2014). However, the fact that most of the observational records do not begin until the 1950s (González-Hidalgo et al., 2011) is limiting the possibility of investigating the interannual to multi-centennial long-term temperature variability. Therefore, it is crucial to explore climate proxy data and develop long-term reconstructions of regional temperature variability to evaluate spatial patterns of climatic change and the role of natural and anthropogenic forcings on climate variations (Büntgen et al., 2005). In the IP, much progress has been made to reconstruct past centuries climate variability, including analysis of documentary evidence for temperature (i.e., Camuffo et al., 2010) and drought reconstruction (i.e., Barriendos, 1997; Vicente-Serrano and Cuadrat, 2007; Domínguez-Castro et al., 2010). Additionally, progress has been made in further understanding long-term climate variability in the IP through dendroclimatological studies focussing on drought (Esper et al., 2014; Tejedor et al., 2016) 


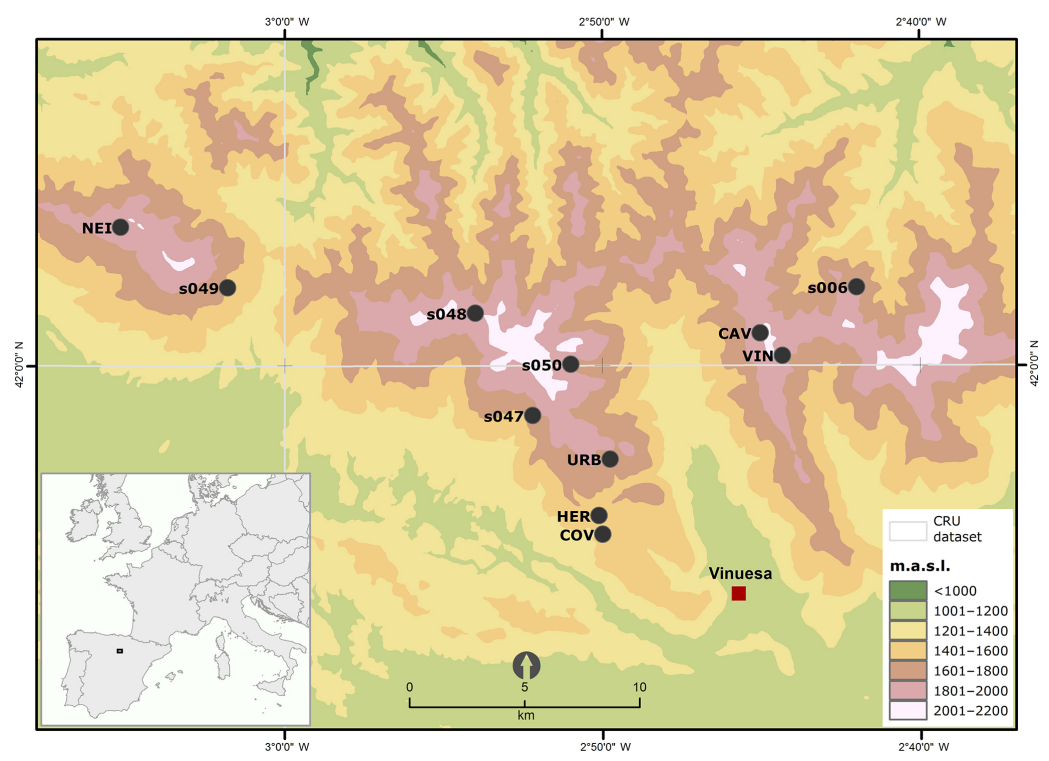

Figure 1. Map showing the tree-ring study sites and the climate data (CRU TS v.3.22) grid points in the western Iberian Range (Soria).

and temperature (Büntgen et al., 2008; Dorado Liñán et al., 2012, 2014; Esper et al., 2015a). Nevertheless, a temperature reconstruction for central Spain is still missing.

Several studies have been made to develop a temperature reconstruction for the Iberian Range (IR; see Fig. 1) using Pinus uncinata tree-ring data (Creus and Puigdefabreas, 1982; Ruiz, 1989). The results, in fact, showed a pronounced interannual- to century-scale chronology variability. However, their main result was a complex growth response function due to a mixed climate signal instead of a temperature reconstruction. Furthermore, Saz (2003) developed a 500-year temperature reconstruction for the Ebro Depression (north of Spain), but this chronology is based on a reduced number of cores and a standardized methodology that did not retain the medium- and low-frequency variance.

Here we present the first tree-ring dataset combining samples from three different sources from the eastern IR extending back from the Little Ice Age (1465) to present (2012). The aim of this study is to develop a temperature reconstruction representing the IR, and thereby fill the gap between records located in the northern and southern IP. A new methodology, based on basal area instead of the cambial age, was applied to preserve high- to low-frequency variance in the resulting chronology. Furthermore, the relationship between the tree-ring and climate data is reanalyzed by adding memory to the climate parameters, since memory effects on tree-ring data are much less acknowledged (Anchukaitis et al., 2012). This analysis is challenging because of the mix of tree species and their unidentified responses to climate. The resulting reconstruction of September maximum temperatures over the past four centuries is compared with latest findings from the Pyrenees and Cazorla as well as with the relationship with solar and volcanic forcings at interannual to multi-decadal timescales.

\section{Material and methods}

\subsection{Site description}

We compiled a tree-ring network from 11 different sites in the western IR (Table 1) in the province of Soria. Urbión is the most extensive forest of the IP including 120000 ha between the Burgos and Soria provinces. It has a long forest management tradition. Therefore, all sites are situated at high-elevation locations where forests are least exploited and maximum tree age is reached (Fig. 1). The altitude of the sampling sites ranges from 1500 to $1900 \mathrm{~m}$ above sea level (m a.s.l.) with a mean of $1758 \mathrm{~m}$ a.s.l. These forests belong to the continental bioclimatic belt (Guijarro, 2013), characterized by moderate mean temperatures $\left(9.5^{\circ} \mathrm{C}\right.$, Fig. $\left.2 \mathrm{~b}\right)$ and a large seasonal range including more than 90 frost days and summer heat exceeding $30^{\circ} \mathrm{C}$. Mean annual precipitation for the period 1944-2014 is $927 \mathrm{~mm}$ (CRU TS.3 v.23 dataset by Harris et al., 2014) and reaches its maximum during December (Fig. 2a, c).

Although Scots pine (Pinus sylvestris) is the dominant tree species of the region, other pines are found such as $P i$ nus pinaster, Pinus nigra, or Pinus uncinata. What is especially remarkable is the occurrence of Pinus uncinata growing above $1900 \mathrm{~m}$ a.s.l. and reaching its European southern distribution limits in the IR. The lithology of the study area consists of sandstones, conglomerates, and lutites. 
Table 1. Tree-ring sites' characteristics.

\begin{tabular}{|c|c|c|c|c|c|c|c|c|c|c|}
\hline Code & Site & Source & Lat & Long & Elevation & Species & Tree no. & Sample no. & Tree rings & Period \\
\hline s048 & Urbión Duruelo & ITRDB & 42.02 & -2.90 & 1840 & PISY & 8 & 17 & 3590 & $1671-1983$ \\
\hline s049 & Urbión Quintenar & ITRDB & 42.03 & -3.03 & 1840 & PISY & 12 & 27 & 4713 & $1593-1985$ \\
\hline s050 & Urbión Vinuesa & ITRDB & 42.00 & -2.85 & 1750 & PISY & 4 & 8 & 1942 & $1681-1983$ \\
\hline s006 & Urbión & ITRDB & 42.03 & -2.7 & 1634 & PISY & 11 & 22 & 2397 & $1842-1977$ \\
\hline CAV & Castillo de Vinuesa & UNIZAR & 42.01 & -2.75 & 1900 & PIUN & 18 & 36 & 9236 & $1593-2012$ \\
\hline $\mathrm{COV}$ & Covaleda & IPE-CSIC-UNIZAR & 41.93 & -2.83 & 1500 & PISY & 16 & 48 & 14696 & $1568-1993$ \\
\hline URB & Picos de Urbión & UNIZAR & 41.96 & -2.82 & 1750 & PISY & 28 & 60 & 11328 & $1733-2012$ \\
\hline \multirow[t]{2}{*}{ VIN } & Castillo de Vinuesa & IPE-CSIC-UNIZAR & 42.03 & -2.73 & 1900 & PIUN & 13 & 20 & 7653 & 1465-1992 \\
\hline & & & & & & Total & 159 & 316 & 76273 & \\
\hline
\end{tabular}

UNIZAR, University of Zaragoza; IPE-CSIC, Spanish National Research Council; ITRDB, International Tree-Ring Data Bank.
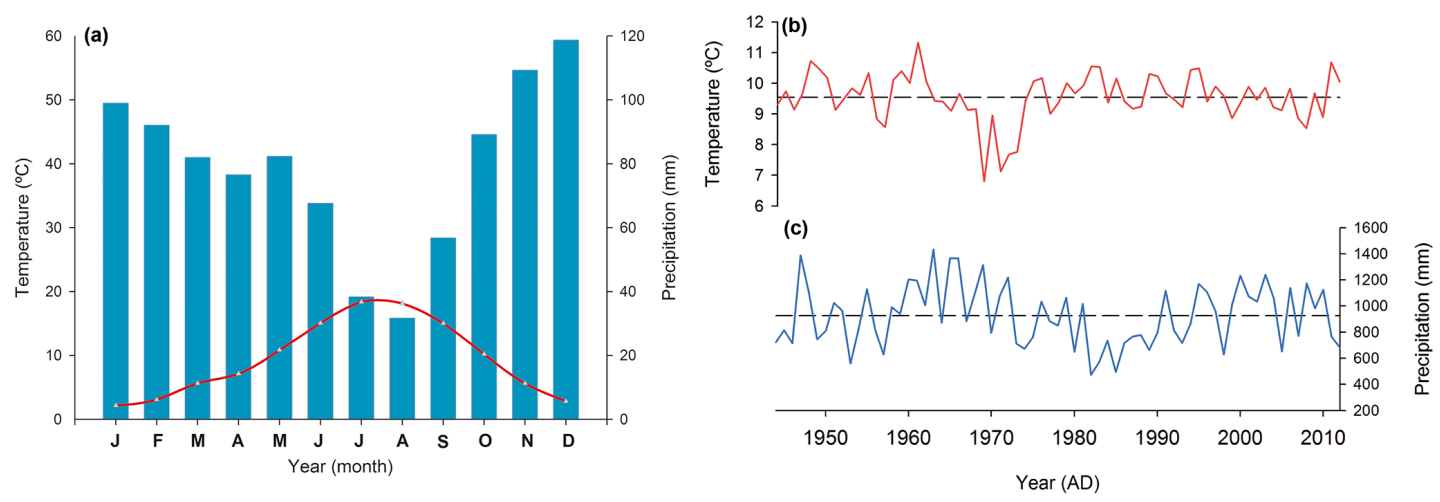

Figure 2. Climate diagram (a), mean temperature (b), and mean precipitation (c) calculated using data from CRU TS v.3.22 over the period 1944-2012 (Harris et al., 2014).

\subsection{Tree-ring chronology development}

The new dataset is composed by 316 tree-ring width (TRW) series of Pinus uncinata (56) and Pinus sylvestris (260) located in the western IR (Table 1, Fig. 1). The most recent samples were collected during the field campaign in 2013, including old dominant and co-dominant trees with healthy trunks and no sign of human interference. We extracted two core samples from each tree at breast height $(1.3 \mathrm{~m})$ when possible; otherwise, we tried to avoid compression wood due to steep slopes, compiling a set of 96 new samples from two sites, with the outermost ring being 2012. Core samples were air-dried and glued onto wooden holders and subsequently sanded to ease growth ring identification (Stokes and Smiley, 1968). The samples were then scanned and synchronized using CoRecorder software (Larsson, 2012) (Cybis Dendrochronology, 2014) to identify the position and exact dating of each ring. The tree-ring width was measured, at $0.01 \mathrm{~mm}$ precision, using a LINTAB table (Rinn, 2005). Prior to detrending, COFECHA (Holmes, 1983) was used to assess the cross-dating of all measurement series.

An additional set of 95 samples from three sites was provided by the project CLI96-1862 (Creus et al., 1992; Saz, 2003); the outermost rings range from 1992 to 1993. Finally, a set of 125 samples from five sites was downloaded from the International Tree Ring Data Bank (ITRDB, http://www.ncdc.noaa.gov/data-access/ paleoclimatology-data/datasets/tree-ring). These data were developed in the 1980s by K. Richter and collaborators; the outermost rings range from 1977 to 1985.

In order to attempt a climate reconstruction for the western IR from this tree-ring network, we perform an exploratory analysis of the 11 tree-ring sites by creating a correlation matrix of the raw TRW series for each site and the correlation with a composite regional chronology. Calculations are computed for the common period (1842-1977) and for the full period (1465-2012).

\section{Standardization methods}

The key concept in dendroclimatology is referred to as the standardization process (Fritts, 1976; Cook et al., 1990), where the aim is to preserve as much of the climate-related information as possible while removing the non-climatic information from the raw TRW measurements. However, with 
most of the standardization methods a varying proportion of the low-frequency climatic information is also lost in the process (Grudd, 2008). When the aim is to use tree-ring chronologies as a proxy for climatic reconstructions, an adequate standardization is critical and the best method should preserve high- to low-frequency variations (Büntgen et al., 2004). It is common practice to calculate a mean value function as the best estimate of the trees' signal at a site (Frank et al., 2006).

We here applied four standardization methods to the 316 TRW measurement series to develop a single tree-ring index chronology. (i) To emphasize interdecadal and higherfrequency variations, each ring width series was fitted with a cubic spline with a $50 \%$ frequency response cut off at $67 \%$ of the series length (Cook et al., 1990). A bi-weight robust mean was calculated to assemble the ArstanSTD regional chronology. (ii) A residual chronology (ArstanRES) is produced after removing first-order autoregression to emphasize high-frequency variability. (iii) To preserve common interdecadal and lower-frequency variations, regional curve standardization (RCS) was applied (Mitchell, 1967; Briffa et al., 1992; Esper et al., 2003). RCS is an age-dependent composite method and involves dividing the size of each treering by the value expected from its cambial age. To assemble the chronology, all the series are aligned by cambial age. A single growth function (regional curve, RC) smoothed using a spline function of $10 \%$ of the series length is fit to the mean of all age-aligned series. A biweight robust mean was applied to develop the RCS chronology (RCS). (iv) To preserve high- to low-frequency variance, we additionally applied a novel standardization method based on the principles of RCS. However, instead of using the cambial age of the trees as the independent variable, we used their sizes, calculated as the basal area of the tree in the year prior to ring formation. Then, a Poisson regression model was used to fit the individual tree-ring widths. Standardized indices were calculated as the ratio between the observed and predicted values, and a biweight robust mean was used to develop the basalarea Poisson chronology (BasPois).

To evaluate uncertainty in the mean chronologies, running interseries correlations (Rbar) and the express population signal (EPS) were calculated (Wigley et al., 1984). Rbar is a measure of the strength of the common growth "signal" within the chronology (Wigley et al., 1984; Briffa and Jones, 1990), here calculated in a 50-year window sliding along the chronology. EPS is an estimate of the chronology's ability to represent the signal strength of a chronology on a theoretically infinite population (Wigley et al., 1984).

\subsection{Climatic data, calibration, and climate reconstruction}

Monthly temperature (mean, maximum, and minimum) and precipitation values from the gridded CRU TS v.3.22 dataset $\left(0.5^{\circ}\right.$ resolution) dataset for the period 1945-2012 were used (Harris et al., 2014). The three grid points closest to

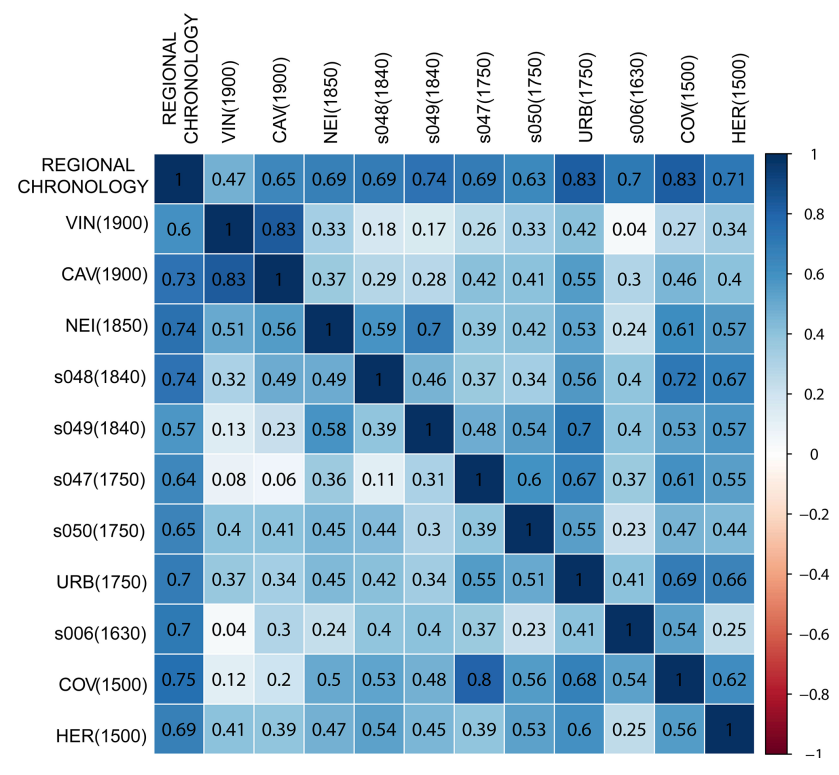

Figure 3. Correlation of the raw chronologies sorted by elevation. Top right shows the correlations calculated over the common period 1842-1977. Bottom left shows the correlation over the full period of overlap between pairs of chronologies

the tree-ring network were averaged to develop a regional time series (Fig. 1). In addition, we calculate a cumulative monthly mean for each of the four parameters (max., min., mean temperature, and monthly precipitation). The cumulative mean is calculated by adding the months gradually. First the previous month is added, and then further months are included up to 36 previous months. For the calculations we take into account the current and the previous year. To indicate the climate parameter an abbrevia-

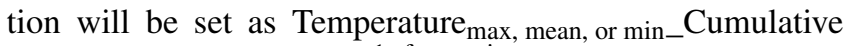
months_Calendar month ${ }^{-1}$, for previous year. For instance, the maximum temperature of the previous year October with 20 months of cumulative monthly mean will be referred to as $T_{\max } \_20 \_$Oct $^{-1}$.

For calibration, we correlated the four chronologies (ArstanSTD, ArstanRES, RCS, and BasPois) with monthly climate data and the cumulative monthly mean derived. However, to be consistent statistically, the two chronologies which highlight high-frequency variations, ArstanRES and ArstanSTD, were correlated with the detrended climatic data. To assess the stability of the correlation, we calculated a 30year moving correlation shifted along 1945-2012 with the cumulative monthly mean from the current and the previous year. In addition, the maximum and minimum differences between the moving correlations were calculated. As a result, the climatic variable chosen for the reconstruction is supported by having the highest moving correlation with the least difference between the maximum and the minimum over the moving correlation period. 

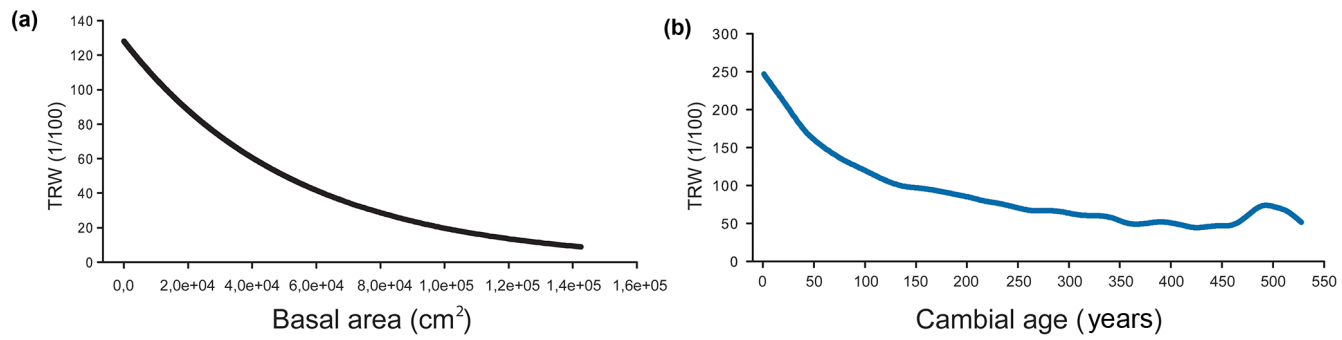

Figure 4. Panel (a) represents the model of the BasPois method, and (b) represents the regional curve of the RCS method.

A split calibration/verification approach was perform over the periods 1945-1978 and 1979-2012 to evaluate the accuracy of the transfer model considering the following metrics; Pearson's correlation $(r)$, coefficient of determination $\left(r^{2}\right)$, reduction of error (RE), mean square error (MSE), the sign test (Cook et al., 1994), and the Durbin-Watson test (Durbin and Watson, 1951). $R$ is a measure of the linear correlation between the chronology and climatic variable. $R^{2}$ indicates how well the data fit a statistical model. An $r^{2}$ of 1 indicates that the regression line perfectly fits the data; an $r^{2}$ of 0 indicates that there is not fit at all. RE compares the skill of the estimated values with that obtained by using the mean value of the calibration period for every year. It is particulary useful since it checks whether a proxy is able to follow the lower-frequency changes in climate between the calibration and verification periods (Wahl and Amman, 2007) and hence it provides a sensitive measure of the reliability of a reconstruction (Cook et al., 1994; Akkemik et al., 2005; Büntgen et al., 2008); it ranges from +1 , indicating perfect agreement, to minus infinity. MSE estimates the difference between the modeled and measured while sign test compares the number of agreeing and disagreeing interval trends, from year to year, between the observed and reconstructed series (Fritts et al., 1990; Čufar et al., 2008). To verify that there is no autocorrelation in the residuals we perform the Durbin-Watson test. Additionally, a superposed epoch analysis (SEA; Panofsky and Brier, 1958) was performed using dendrochronology program library in R (dplR) (Bunn, 2008) to assess postvolcanic cooling signals in our reconstruction. The approach has been used in studies of volcanic effect on climate (Fischer et al., 2007; D'Arrigo et al., 2009; Esper et al., 2013a, b). The major volcanic events chosen for the analysis were those identified by Crowley (2000), in order of magnitude $(1815,1641,1809,1831,1992,1883,1902,1695,1674$, and 1783).

To transfer the TRW chronology into a temperature reconstruction a linear regression model was used. The temperature was set as the dependent variable and the chronology as the independent variable, and then we used ordinary least squares assuming Gaussian independent errors to estimate the regression coefficient. The magnitude and the spatial extent of the climate signal are evaluated considering the CRU TS v. 3.22 gridded dataset for Europe.

\section{Results}

The correlation matrix (Fig. 3) shows not only the high intercorrelation between sampling sites and tree species but also the high correlation between each chronology and the regional chronology. The highest correlation is found within Pinus uncinata (VIN and CAV) located at the highest altitude. On the other hand, the weakest correlation is found between one of the lowest sites (s006) and the highest (VIN). The mean correlation among all sampling sites is $r=0.51$ over the common period (1842-1977) is 0.51 , and $r=0.46$ over the full period of overlap, revealing a regionally common, external forcing controlling tree growth and justifying the development of a single chronology integrating the data from this IP tree-ring network.

The model (regional curve) of the RCS method and the model of the BasPois method are presented in Fig. 4. The BasPois model (Fig. 4a) indicates a growth of $130 \mathrm{~mm}$ when the size of the basal area is near 0 and a growth of $8 \mathrm{~mm}$ when it reaches the maximum basal area. RCS model (Fig. 4b) presents values of $250 \mathrm{~mm}$ of growth when the cambial age is 0 with a gradual decline in the growth until the cambial age of 450. At cambial ages from 500 to 550, a slight increase in growth is observed that is most likely derived by low replication regarding trees with these ages. The four chronologies after different detrending methods are shown in Fig. 6.

Calibration of the four differently detrended mean chronologies reveals a highly negative correlation with monthly mean of daily maximum temperatures (Fig. 5). The ArstanRES chronology shows moderate correlations with previous-year September $(r=-0.39)$, and the ArstanSTD chronology correlates at $r=-0.56$ with both $T_{\max \_} 21 \_S p^{-1}$ and $T_{\max \_} 21 \_\mathrm{Oct}^{-1}$. Considering the RCS chronology, the $T_{\max } 21 \_S^{-} p^{-1}$ signal increases to $r=-0.57$. Finally, the best correlation is revealed for the BasPois chronology reaching $r=-0.78$ with $T_{\max \_21 \_S e p}{ }^{-1}$, which is, in fact, a 2 -year cumulative monthly mean. Even though the signals show the same seasonal patterns among the chronologies, the BasPois record always shows the highest correlations. Accordingly, we used the BasPois chronology for the calibration and reconstruction process. 

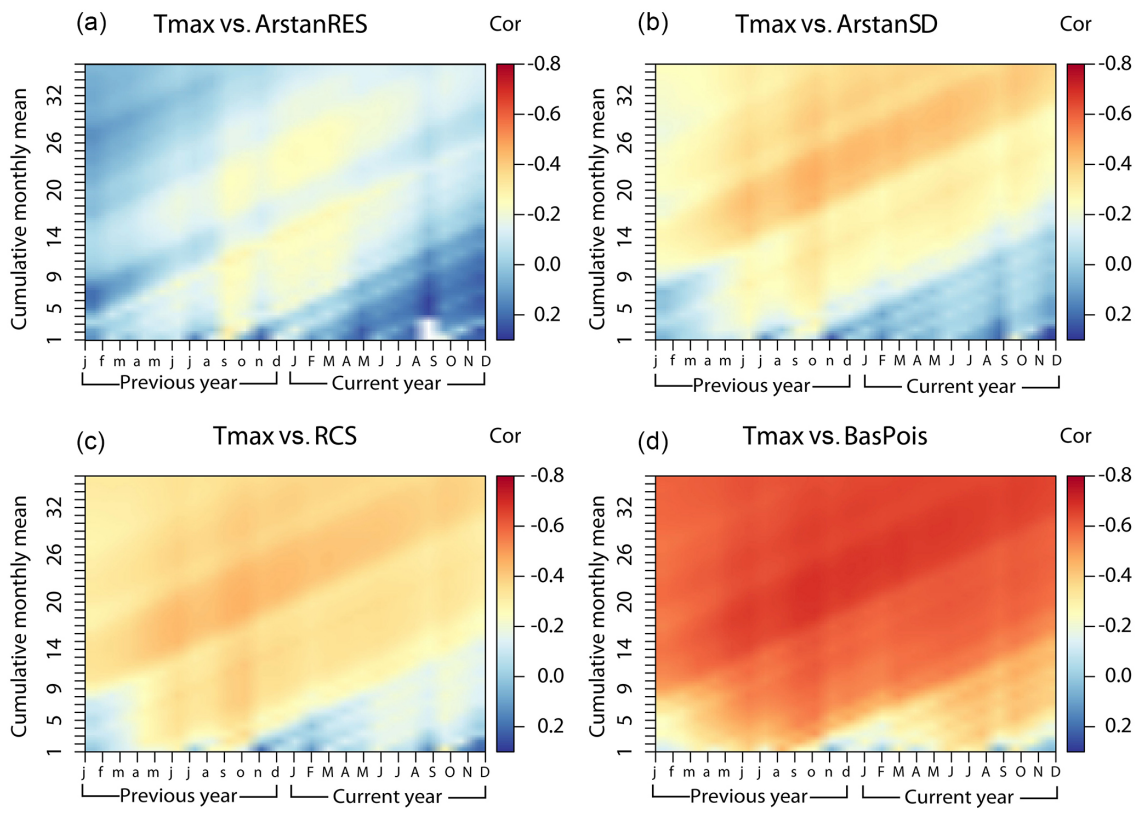

Figure 5. Correlation between the monthly mean of daily maximum temperature (from January of the previous year to December of the current year with a cumulative monthly mean from 1 to 36 months) and the residual Arstan chronology (a), the standard Arstan chronology (b), the RCS standard chronology (c), and the basal-area Poisson standard chronology (d).

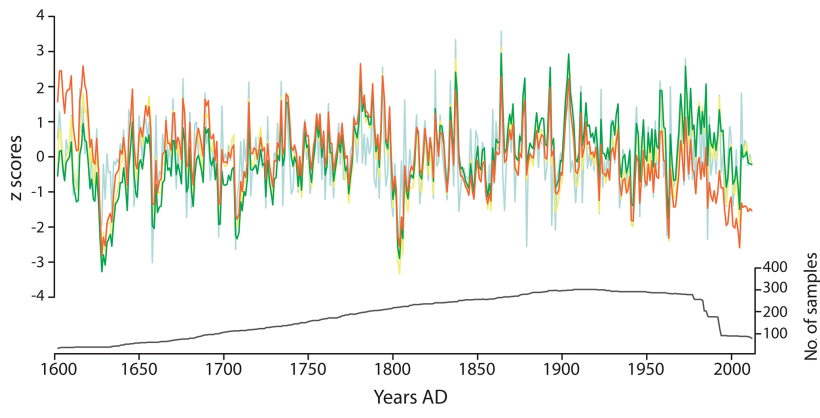

Figure 6. The four chronologies after different detrending methods for the EPS $>0.85$ period; BasPois chronology (in orange), RCS chronology (in green), ArstanSTD chronology (in yellow), ArstanRES chronology (in blue), and number of samples (in black).

The final BasPois network chronology (Fig. 6) is based on 316 TRW series of Pinus uncinata and Pinus sylvestris spanning the 1465-2012 period. Since this chronology is derived from only living trees, mean chronology age increases from 47 years in 1966 to 528 in 1465 . The mean sensitivity is 0.21 , the first-order autocorrelation is 0.83 and the interseries correlation (Rbar) reaches 0.26 . The network chronology's signal-to-noise ratio is 48.52 , and EPS exceeds 0.85 after 1602 , constraining the reconstruction period to 410 years until 2012.

The selection of the best climate parameter to develop the reconstruction is presented in the Fig. 7, where correlations between -0.54 and -0.86 , representing only the most signif- icant values, are shown. Four parameters reveal the highest correlations over the full calibration period: $T_{\max } 22$ 2_Oct,

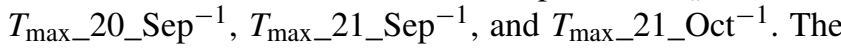
stability of the correlation and therefore the consistency of the signal are tested considering the minimum difference between the maximum and minimum correlation (Fig. 7b) over the full running correlation period. The smallest difference (0.24) is reached for September of the previous year with a cumulative monthly mean of 21 months. Therefore, this parameter is chosen for the climate reconstruction. According to the 30-year moving correlations, maximum values are reached from 1973 to $2003(r=-0.80)$, whereas the lowest 30-year correlation $(r=-0.60)$ is reached from 1956 to 1986. In addition, the relationship between $T_{\max \_} 21{ }_{-} S p^{-1}$ is spatially consistent throughout the Iberian Peninsula, reaching into southern France and northern Africa (Fig. 11).

The transfer model is validated by the high correlation $(r=-0.78)$ and significant coefficient of determination $\left(r^{2}=0.61\right)$ over the full period 1945-2012. Through the split calibration/verification process, considering 1945-1978 and 1979-2012, the temporal robustness was tested, revealing highly significant correlations for both periods $\left(r^{2}=0.41\right.$ and $r^{2}=0.55$, respectively) and verifying the final reconstruction (Table 2 and Fig. 8). The Durbin-Watson test for the full period $(1.45 p<0.0001)$ indicates no substantial autocorrelation in the residuals. To develop the final reconstruction spanning 1602-2012, we used a lineal regression model over the full period 1945-2012 with maximum temperature of September of the previous year with a cumulative monthly 
Table 2. Calibration/verification statistics of the IR2Tmax reconstruction.

\begin{tabular}{lrrrrr}
\hline & $\begin{array}{r}\text { Calibration } \\
1945-1978\end{array}$ & $\begin{array}{r}\text { Verification } \\
1978-2012\end{array}$ & $\begin{array}{r}\text { Calibration } \\
1979-2012\end{array}$ & $\begin{array}{r}\text { Verification } \\
1945-1978\end{array}$ & $\begin{array}{r}\text { Period } \\
1945-2012\end{array}$ \\
\hline Years & 34 & 34 & 34 & 34 & 68 \\
Correlation & -0.64 & 0.73 & -0.74 & 0.64 & -0.78 \\
$R^{2}$ & 0.41 & 0.55 & 0.55 & 0.41 & 0.61 \\
MSE & 0.43 & 0.42 & 0.42 & 0.43 & 0.43 \\
Reduction of error & 0.40 & 0.65 & 0.65 & 0.40 & 0.56 \\
Sign test D & $28+/ 6-$ & $24+/ 10-$ & $28+/ 6-$ & $24+/ 10-$ & $52+/ 16-$ \\
Durbin-Watson & $1.31 p<0.01$ & $1.53 p<0.05$ & $1.53 p<0.05$ & $1.31 p<0.01$ & $1.45 p<0.001$ \\
\hline
\end{tabular}

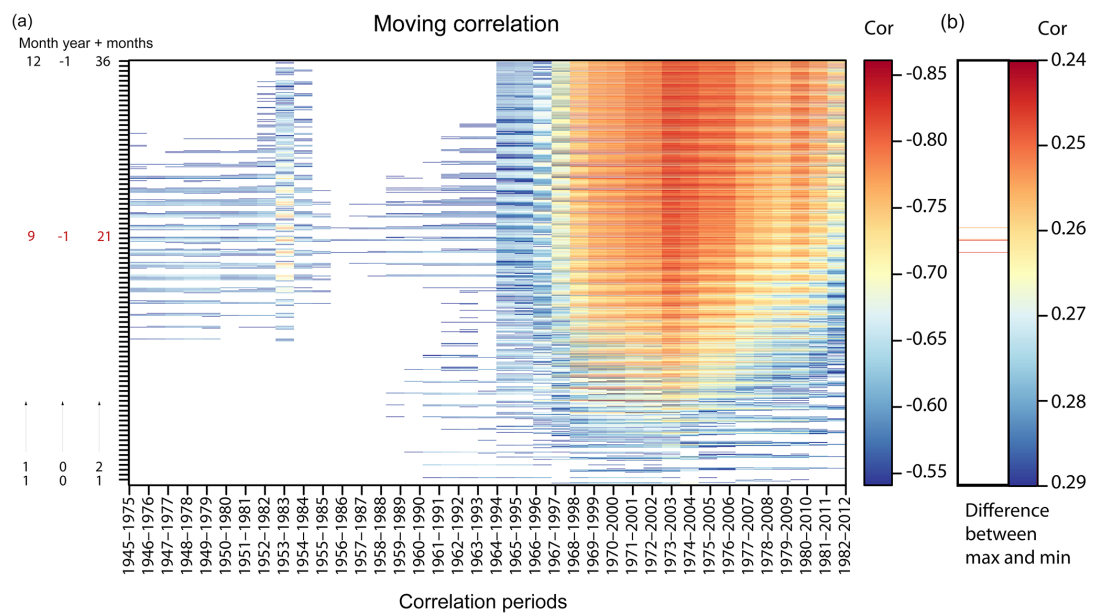

Figure 7. (a) Thirty-year moving correlation from 1945 to 2012 between the monthly mean of daily maximum temperature, from January of the current year $(1,0,1)$ to December of the previous year $(12,-1,36)$ with a cumulative monthly mean from 1 to 36 months and the BasPois chronology. Red numbers indicate the chosen climatological parameter: 9, September, -1 , previous year, 21 , months used for the cumulative monthly mean. (b) The four best parameters are represented. The reddish line indicates the least difference between the maximum and minimum correlation in the correlation periods.

mean of 21 months (Eq. 1), denoted IR2Tmax:

$$
\begin{aligned}
\operatorname{IR2Tmax} & =-3.9759 \cdot \text { BasPoisChron } \\
& +15.769\left(r^{2}=0.61 ; p<0.0001\right) .
\end{aligned}
$$

\subsection{IR2Tmax reconstruction}

IR2Tmax describes 410 years of maximum temperature of $T_{\text {max_21_Sep }}{ }^{-1}$, meaning it has memory of the last 2 years. Biennial temperature ranges from $13.52{ }^{\circ} \mathrm{C}\left(-2.13{ }^{\circ} \mathrm{C}\right.$ with respect to the mean) in 1603 to $17.64{ }^{\circ} \mathrm{C}\left(+1.94{ }^{\circ} \mathrm{C}\right.$ with respect to the mean) in 2005 (Fig. 9). It is remarkable that, from 1602,12 of the 25 warmest biennial periods happen during the 20th and 21st centuries. IR2Tmax covers a part of the Little Ice Age (Grove, 1998) from 1602 to the end of the 19 th century. The temperature variability is $3.92^{\circ} \mathrm{C}$ in the 17 th century, $2.89^{\circ} \mathrm{C}$ in the 18 th century, $3.17^{\circ} \mathrm{C}$ in the 19 th century and $3.07^{\circ} \mathrm{C}$ in the 20th century. The 17th and 18th centuries were the coldest of the reconstruction with 73 and
$80 \%$ of the biennials with temperatures below the long-term mean, respectively. On the other hand, the 19th and the 20th centuries were the warmest, with 66 and $78 \%$ of the biennial periods exceeding the mean.

The main driver of the large-scale character of the warm and cold episodes may be changes in the solar activity (Fig. 9). The beginning of the reconstruction starts with the end of the Spörer minimum. The Maunder minimum, from 1645 to 1715 (Luterbacher et al., 2001) seems to be consistent with a cold period from 1645 to 1706 . In addition, the Dalton minimum from 1796 to 1830 is detected for the period 1810 to 1838 . However, a considerably cold period from 1778 to 1798 is not in agreement with a decrease in the solar activity. Four warm periods - 1626-1637, 1800-1809, 18451859, and 1986-2012 - have been identified to correspond to increased solar activity. Overall, the correlation between the reconstruction and the solar activity is $0.34(p<0.0001)$, which increases to $r=0.49$ after 11 -year low-pass filtering of the series, though the degrees of freedom are substantially reduced due to the increase autocorrelation. 


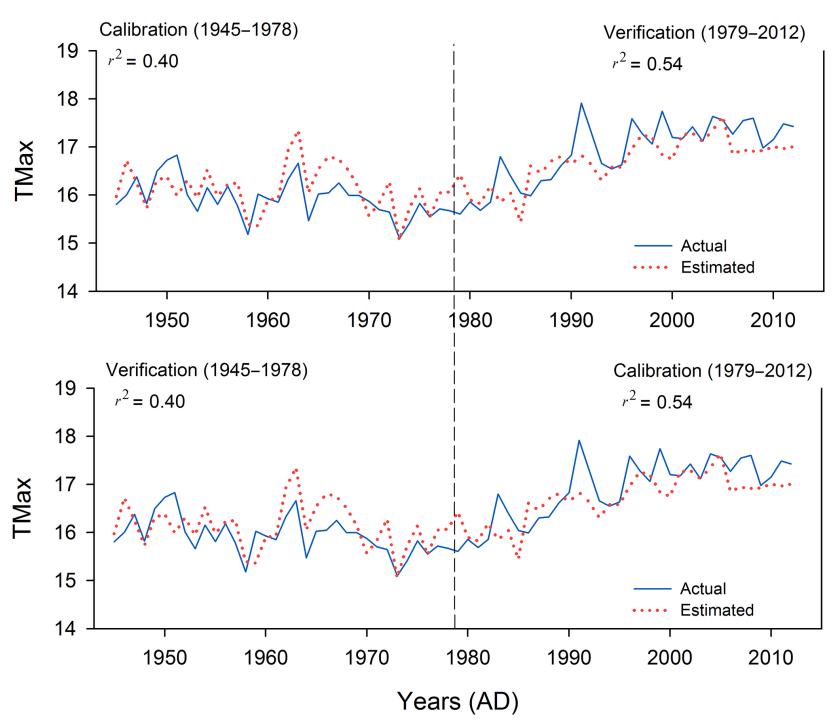

Figure 8. Calibration and verification results of the CRU data-based $T_{\max \_21 \_S e p}{ }^{-1}$ reconstruction.

The SEA (Fig. 10) indicates some impact of volcanic eruptions on the short-term temperature variability within the reconstruction. It shows significance $(p<0.05)$ decrease in September's temperature with a lag of 3 years.

Figure 11 shows the spatial correlation between the reconstruction and the CRU TS v.3.22 for Europe and northern Africa. A high coefficient of determination $\left(r^{2}>0.4\right.$, $p<0.0001)$ indicates a robust agreement and spatial extent of the reconstruction over the Iberian Peninsula (IP), especially for the central and Mediterranean Spain. The spatial correlation, however, decreases towards the southwest of the IP and the north of Europe.

\section{Discussion and conclusion}

A novel detrending approach, considering a basal-area Poisson model (BasPois) instead of the traditional regional curve (Esper et al., 2003), has certainly improved the skill of the reconstruction and enabled retaining high- to low-frequency climate variance. The traditional approach of using RCS with the mean TRW curve of the age-aligned data only reached correlations with the $T_{\max \_21 \_S e p}{ }^{-1}$ up to $r=-0.57$, while with the new approach reached $r=-0.78$.

Observed improvements in the reconstruction's skills associated to the BasPois detrending approach need to be determined in other species and environmental conditions. However, several theoretical and practical advantages can be highlighted: (1) similarly to RCS, BasPois used all individual tree-ring measurements to complete a single detrending. High but also medium- and low-frequency variability is then successfully preserved in the chronology in a similar way as has been described for the RCS method. (2) Removing biological trends from raw tree-ring measurements rep- resents the key objective of the detrending processes. However, it is usually difficult to determine the extent to which the effects of environmental factors on tree growth depend on age (genetic control) and/or on size (physiological control). Recent investigations suggest that key functional processes (and therefore potential physiological constraints) on trees are more dependent on their size than on their age (Mencuccini et al., 2005; Peñuelas, 2005). Climate growth relationships have indeed demonstrated to be strongly dependent on the size of the trees, with the differences between size classes even greater than the differences found amongst age classes or even between different species (de Luis et al., 2009). Hence, the size-based standardization considered in the BasPois approach could represent a suitable alternative to age-based standardization processes (such as RCS) in order to isolate the evidence of external, climatically driven forcing of tree growth. (3) By using standard dendrochronological samples, it is usually not possible to exactly determine the age of the trees and subsequently the cambial age of each individual tree ring. As a consequence, age-based standardization processes should be often based on age estimations instead of directly measured values. However, the diameter at breast height $(\mathrm{DBH})$ is a parameter that is routinely obtained during the dendrochronological sampling, and then the size of each tree prior to the formation of any tree ring can be directly and unequivocally determined. (4) Finally, a clear additional advantage is related to the possibility to design a sampling strategy including trees of different size classes in order to obtain a more unbiased distribution of tree rings in relation to the independent variable used for the detrending. To the best of our knowledge, size-based standardization processes as tested for our database have not been applied elsewhere. Further research is needed to generalize the advantages of such an approach.

According to the previously discussed novel detrending approach and based on a coherent network of 11 tree-ring sites in the IR including 316 TRW series, we developed a 410-year maximum September temperature reconstruction. This record is the first climate reconstruction for the IR filling the gap between the temperature reconstructions developed for the north IP (Büntgen et al., 2008; Dorado Liñán et al., 2012; Esper et al., 2015a) and for the southern IP (Dorado Liñán et al., 2014). The IR2Tmax has been achieved using TRW, which is the same parameter used for the southern IP (Dorado Liñán et al., 2014). However, for the Pyrenees, maximum latewood density (MXD) (Büntgen et al., 2008; Dorado Liñán et al., 2012) or stable isotopes (Esper et al., 2015a) are needed to get skillful records for a temperature reconstruction.

The main statistics used to verify the accuracy of the reconstruction present similar values to those developed for the IP. For instance, the RE coefficient for the period 1945-2012 is 0.56 , meaning that the reconstruction has indeed useful skills to develop a reconstruction. A relatively high signalto-noise ratio indicates there is meaningful climatic informa- 


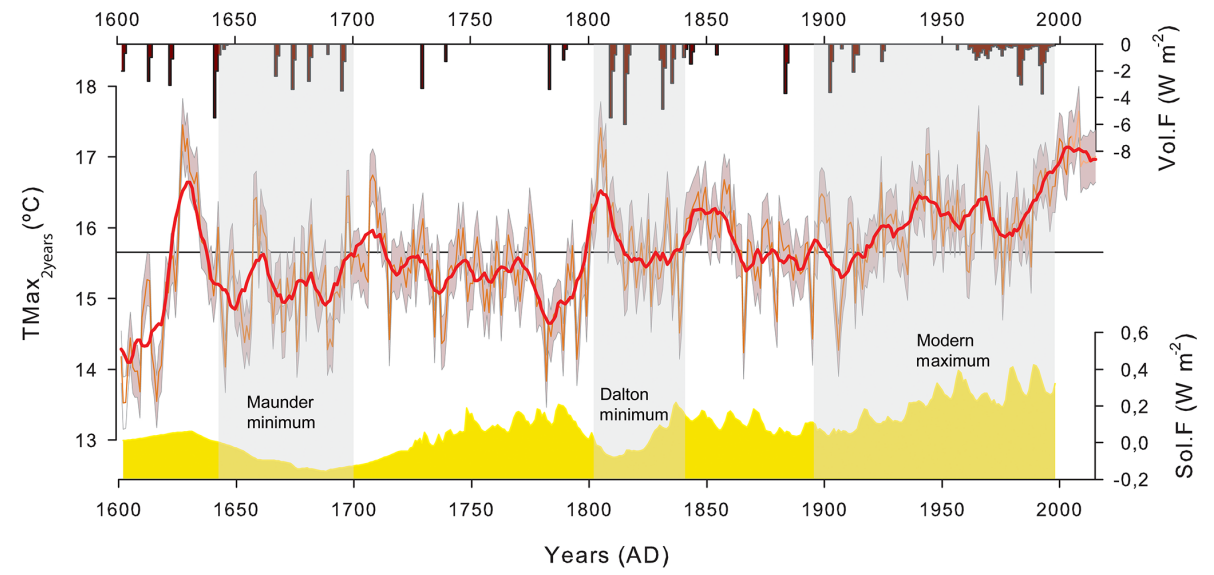

Figure 9. IR2Tmax reconstruction since AD 1602 for the Iberian Range. The bold red curve is an 11-year running mean, and grey shading indicates the mean square error based on the calibration period correlation. Yellow shading at the bottom shows solar forcing and bars on top indicate volcanic forcings (Crowley, 2000).

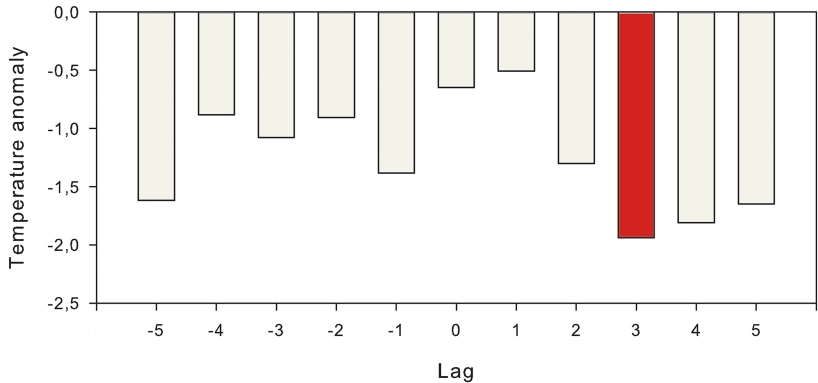

Figure 10. Superposed epoch analysis with a back and forward lag of 5 years. Significance $(p<0.05)$ at 3 years after the extreme volcanic events identified in Crowley (2000).

tion in the chronology. The mean correlation between sites for the common period ( $r=0.51$, Fig. 3) reveals substantial agreement between the sites and species. Correlation is strongest among high-elevation sites, including the sites VIN and CAV, which are both derived from Pinus uncinata. The regional climate variability was retained quite accurately by the mean chronology (including 48.52 of signal to noise), which highlights the beauty of regional averages (Briffa et al., 1998).

The original, raw chronology extended over the 14652012 period, some 150 years longer than the final reconstruction. However, due to low EPS values prior to 1602, which is related to the low number of samples, the final reconstruction was developed for the period 1602-2012.

In this study, we detected a maximum temperature correlation with $T_{\max }$ 21_Sep ${ }^{-1}$ of -0.78 . Nonetheless, the negative temperature correlation is already shown for the previous September ( $r=-0.56$, with BasPoisChron) without any cumulative monthly mean. That would mean that, within the environment in which trees are growing and with respect to the mean, they will grow more in cold than in hot years.
This negative temperature correlation has been reported in numerous dendroclimatic studies (i.e., Büntgen et al., 2007; van der Werf et al., 2007), including the most recently developed climatic reconstruction for the Iberian Peninsula by Dorado Liñán et al. (2014) showing a negative correlation with previous summer temperatures. One of the strengths of the results is adding the cumulative monthly mean to the climate variables, which maximizes the correlation to $r=-0.78$.

The development of climate parameters retaining temperature information of the past 2 years is certainly unusual and distinctive. However, memory effects in TRW data can arise from physiological processes already suggested by Schulman (1956) and Matalas (1962). Moreover, it is well known that TRW growth is conditioned by the storage of starch and sugar in parenchyma ray tissue and the remobilization of carbohydrates from root structures that were storage in previous growing seasons (Pallardy, 2010).

In addition, radial growth of trees is strongly conditioned by total needle biomass available in trees at the start of the growing season (Wang et al., 2012). In pine species, mean needle age ranges from 2 to 4 years (Pensa and Jalkanen, 2005) and the amount of needles formed is also controlled by temperature variations during the years of formation. As a consequence, effects of temperature variability occurred several years before tree-ring formation may have played an important role in secondary growth (radial increment) indirectly through their direct effect in primary production (needle formation). Further research and specific experiments are however needed to confirm such influences and determine the physiological mechanisms behind a climate signal that extends back up to 21 months.

Memory effects in TRW data have also been studied regarding the delayed response in TRW (1-5 years) to after volcanic eruptions associated with a decrease in the current year's temperature (D'Arrigo et al., 2013; Esper et al., 


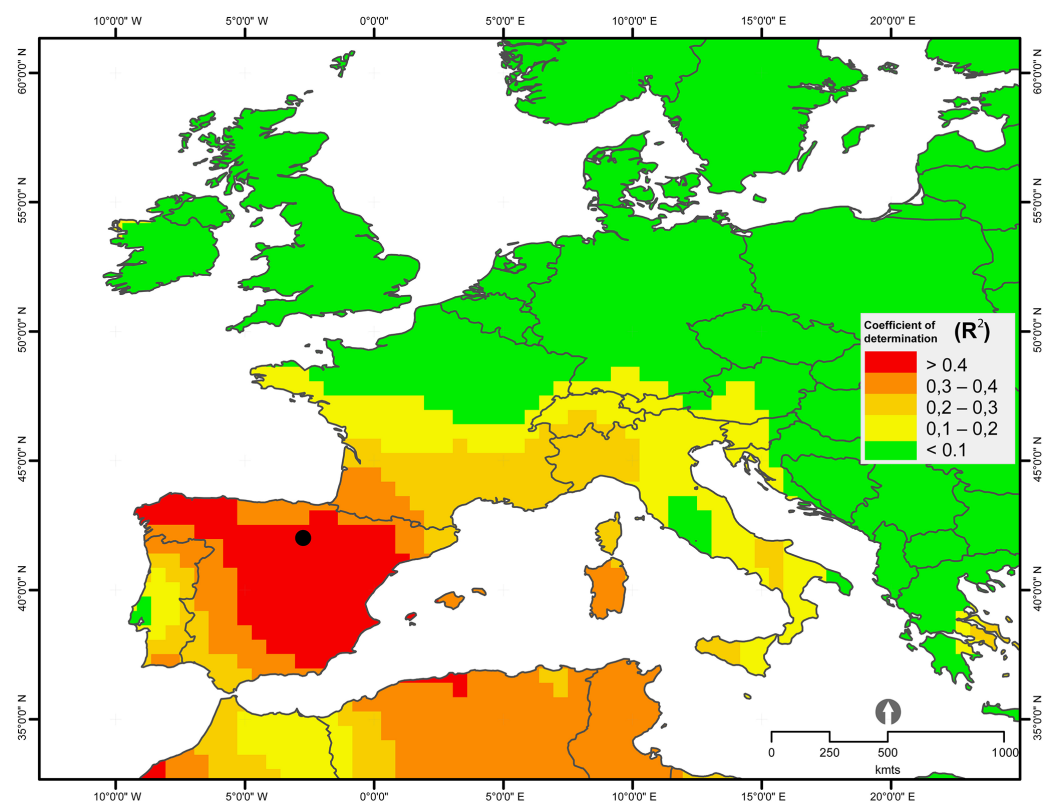

Figure 11. Map showing the spatial correlation patterns of the BasPois chronology with the gridded $T_{\max \_} 21 \_$Sep ${ }^{-1}$. Correlation values are significant at $p<0.0001$.

2015b). Thus, developing the 2-year memory IR2Tmax allowed us to maintain not only the low-frequency signal, highlighting the warm and cold phases, which may be explained by the high correlation with solar activity during 410 years $(0.34, p<0.001)$, but also the high-frequency signal, emphasizing the memory effects of the volcanic eruptions in TRW, already studied by Briffa et al. (1998) and recently by Esper et al. (2015b). According to the SEA (Fig. 9), the volcanic eruptions have a significance reduction $(95 \%$ confidence) of September's temperature $\left(-1.98^{\circ} \mathrm{C}\right)$ with a 3year lag. However, the IR2Tmax already considers the two previous years' temperature, which means the temperature decrease occurred the year after the extreme volcanic event, in consistency with Frank et al. (2007). The stability of the signal was assessed by a 30-year moving correlation from 1945 to 2012, which shows a better correlation for the period 1979-2012 in agreement with the rise in temperatures observed for last decades which may be limiting TRW growth and therefore magnifying the climate signal. However, the relationship between the chronology and the climate parameter chosen never drops below -0.54 within the calibration period 1945-2012. The negative correlation with maximum temperature of previous September is in agreement with the values detected in Cazorla by Dorado Liñán et al. (2014). Presumably, a continuous rise in temperatures, as suggested by the IPCC (2013), would also cause a continuous decrease in tree-ring growth.

Even though the CRU dataset spans the 1901-2013 period, the distribution of meteorological observatories in the Iberian Range of Spain did not begin until the mid-20th century (González-Hidalgo et al., 2011). In fact, the closest in- strumental weather station, located in Vinuesa (Fig. 1), began in 1945. However, due to the large amount of gaps in the time series, the CRU dataset was used instead for the split calibration/verification approach for the period 1945-2012. The advantages of regional climatic averages have already been addressed by Blasing et al. (1981), who stated that the average climatic record of the gridded dataset over the study area is representative of the regional climatic conditions and does not reflect microclimate conditions which may be characteristic of the climatic record at a single station. Tree-ring data might therefore have more variance in common with the regionally averaged climatic record than with the climatic record of the nearest weather station. Generally, studies have shown that the measurements of MXD produce chronologies with an improved climatic signal (Briffa et al., 2002) as it was revealed for summer temperature reconstructions (Hughes et al., 1984; Büntgen et al., 2008; Matskovsky and Helama, 2014). However, based on a TRW chronology, the high correlation coefficient is remarkable for the full calibration period and the CRU dataset $(r=-0.78)$.

Throughout the IR2Tmax reconstruction we identified the main warm and cold phases (Maunder minimum, Dalton minimum) related to long-term temperature variability generally attributed to changes in cycles of solar activity (Lean et al., 1995; Lassen and Friis-Christensen, 1995; Haigh and Cargill, 2015). In addition, similar cold and warm phases are observed comparing with the Pyrenees (Büntgen et al., 2008) and Cazorla (Dorado Liñán et al., 2014) reconstructions. However, prior to the Dalton minimum, a warm phase is detected in IR2Tmax and the Cazorla reconstruction al- 
though it is not present in the Pyrenees or in the Alps (Dorado Liñán et al., 2014).

Through the spatial extent and magnitude of the IR2Tmax reconstruction over Europe, it can be acknowledged that the reconstruction is effective and usable for most of the Spanish Iberian Peninsula and works especially well for the central and Mediterranean Iberian Peninsula, with a very high coefficient of determination $\left(r^{2}>0.4\right)$.

\section{Data availability}

The data used for this study can be downloaded at http://www.dendroteam.com/\#download-data (Tejedor et al., 2017).

Competing interests. The authors declare that they have no conflict of interest.

Acknowledgements. This study was supported by the Spanish government through the projects "CGL2011-28255" and "CGL2015-69985" and by the government of Aragon through the program of research groups (group Clima, Cambio Global y Sistemas Naturales, BOA 147 of 18-12-2002) and FEDER funds. Ernesto Tejedor is supported by the government of Aragon with a PhD grant. Fieldwork was carried out in the province of Soria; we are most grateful to its authorities for supporting the sampling campaign. We are thankful to Klemen Novak, Edurne Martinez, Luis Alberto Longares, and Roberto Serrano for help during fieldwork. We would also like to thank the anonymous reviewers for their insightful comments, as these comments led to improvements in our work.

Edited by: V. Rath

Reviewed by: four anonymous referees

\section{References}

Akkemik, Ü., Da deviren, N., and Aras, A.: A preliminary reconstruction (A.D. 1635-2000) of spring precipitation using oak tree rings in the western Black Sea region of Turkey, Int. J. Biometeorol., 49, 297-302, 2005.

Anchukaitis, K. J., Breitenmoser, P., Briffa, K. R., Buchwal, A., Büntgen, U., Cook, E. R., D’Arrigo, R. D., Esper, J., Evans, M. N., Frank, D., Grudd, H., Gunnarson, B. E., Hughes, M. K., Kirdyanov, A. V., Körner, C., Krusic, P. J., Luckman, B., Melvin, T. M., Salzer, M. W., Shashkin, A. V., Timmreck, C., Vaganov, E. A., and Wilson, R. J. S.: Tree rings and volcanic cooling, Nat. Geosci., 5, 836-837, 2012.

Barriendos, M.: Climatic variations in the Iberian Peninsula during the late Maunder minimum (AD 1675-1715): An analysis of data from rogation ceremonies, Holocene, 7, 105-111, 1997.

Blasing, T. J., Duvick, D. N., and West, D. C.: Dendroclimatic calibration and verification using regionally averaged and single station precipitation data, Tree-Ring Bull., 41, 37-43, 1981.
Briffa, K. R. and Jones, P. D.: Basic chronology statistics and assessment, in: Methods of Dendrochronology: Applications in the Environmental Sciences, edited by: Cook, E. R. and Kairiukstis, L. A., 137-152, International Institute for Applied Systems Analysis (IIASA), Kluwer Academic Publishers, Dordrecht, 1990.

Briffa, K. R., Jones, P. D., Bartholin, T. S., Eckstein, D., Schweingruber, F. H., Karlén, W., Zetterberg, P., and Eronen, M.: Fennoscandian summers from ad 500: temperature changes on short and long timescales, Clim. Dynam., 7, 111-119, 1992.

Briffa, K. R., Jones, P. D., Schweingruber, F. H., and Osborn, T. J.: Influence of volcanic eruptions on Northern Hemisphere summer temperature over the past 600 years, Nature, 393, 450-455, 1998.

Briffa, K. R., Osborn, T. J., Schweingruber, F. H., Jones, P. D., Shiyatov, S. G., and Vaganov, E. A.: Tree-ring width and density data around the Northern Hemisphere: Part 1, local and regional climate signals, Holocene, 12, 737-757, 2002.

Bunn, A. G.: A dendrochronology program library in R (dplR), Dendrochronologia, 26, 115-124, 2008.

Büntgen, U., Esper, J., Schmidhalter, M., Frank, D. C., Treydte, K., Neuwirth, B., and Winiger, M.: Using recent and historical larch wood to build a 1300-year Valais-chronology, edited by: Gärtner, H., Esper, J., and Schleser, G., TRACE, 2, 85-92, 2004.

Büntgen, U., Esper, J., Frank, D. C., Nicolussi, K., and Schmidhalter, M.: A 1052-year tree-ring proxy for Alpine summer temperatures, Clim. Dynam., 25, 141-153, 2005.

Büntgen, U., Frank, D. C., Kaczka, R. J., Verstege, A., ZwijaczKozica, T., and Esper, J.: Growth/climate response of a multispecies tree-ring network in the Western Carpathian Tatra Mountains, Poland and Slovakia, Tree Physiol., 27, 689-702, 2007.

Büntgen, U., Frank, D., Grudd, H., and Esper, J.: Long-term summer temperature variations in the Pyrenees, Clim. Dynam., 31, 615-631, 2008.

Camuffo, D., Bertolin, C., Barriendos, M., Dominguez-Castro, F., Cocheo, C., Enzi, S., Sghedoni, M., della Valle, A., Garnier, E., Alcoforado, M. J., Xoplaki, E., Luterbacher, J., Diodato, N., Maugeri, M., Nunes, M. F., and Rodriguez, R.: 500-Year temperature reconstruction in the Mediterranean Basin by means of documentary data and instrumental observations, Climatic Change, 101, 169-199, 2010.

Cook, E. R., Briffa, K., Shiyatov, S., and Mazepa, V.: Tree-ring standardization and growth trend estimation, in: Methods of dendrochronology: applications in the environmental sciences, edited by: Cook, E. R. and Kairiukstis, L. A., Kluwer Academic Publishers, Dordrecht, 104-162, 1990.

Cook, E. R., Briffa, K. R., and Jones, P. D.: Spatial regression methods in dendroclimatology: a review and comparison of two techniques, Int. J. Climatol., 14, 379-402, 1994.

Creus, J. and Puigdefabregas, J.: Climatología histórica y dendrocronología de Pinus uncinata R, Cuad. Investig. Geográfica, 2, 17-30, 1982.

Creus, J., Génova, M., Fernandez-Cancio, A., and Perez-Antelo, A.: New dendrochronologies for Spanish Mediterranean Zone, Lundqua Report, 34, 76-78, 1992.

Crowley, T. J.: Causes of climate change over the past 1000 years, Science, 289, 270-277, 2000.

Čufar, K., de Luis, M., Eckstein, D., and Kajfez-Bogataj, L.: Reconstructing dry and wet summers in SE Slovenia from oak tree-ring series, Int. J. Biometeorol., 52, 607-615, 2008. 
D'Arrigo, R., Wilson, R., and Tudhope, A.: The impact of volcanic forcing on tropical temperatures during the past four centuries, Nat. Geosci., 2, 51-56, 2009.

D’Arrigo, R., Wilson, R., and Anchukaitis, K. J.: Volcanic cooling signal in tree ring temperature records for the past millennium, J. Geophys. Res.-Atmos., 118, 1-11, doi:10.1002/jgrd.50692, 2013.

de Luis, M., Novak, K., Čufar, K., and Raventós, J.: Size mediated climate-growth relationships in Pinus halepensis and Pinus pinea, Trees-Struct. Funct., 23, 1065-1073, 2009.

Domínguez-Castro, F., García-Herrera, R., Ribera, P., and Barriendos, M.: A shift in the spatial pattern of Iberian droughts during the 17th century, Clim. Past, 6, 553-563, doi:10.5194/cp-6-5532010, 2010.

Dorado Liñán, I., Büntgen, U., González-Rouco, F., Zorita, E., Montávez, J. P., Gómez-Navarro, J. J., Brunet, M., Heinrich, I., Helle, G., and Gutiérrez, E.: Estimating 750 years of temperature variations and uncertainties in the Pyrenees by tree-ring reconstructions and climate simulations, Clim. Past, 8, 919-933, doi:10.5194/cp-8-919-2012, 2012.

Dorado Liñán, I., Zorita, E., González-Rouco, J. F., Heinrich, I., Campello, F., Muntán, E., Andreu-Hayles, L., and Gutiérrez, E.: Eight-hundred years of summer temperature variations in the southeast of the Iberian Peninsula reconstructed from tree rings, Clim. Dynam., 44, 75-93, 2014.

Durbin, J. and Watson, G. S.: Testing for Serial Correlation in Least Squares Regression, II. 16, Biometrika, 38, 159-179, 1951.

El Kenawy, A., López-Moreno, J. I., and Vicente-Serrano, S. M.: Trend and variability of surface air temperature in northeastern Spain (1920-2006): Linkage to atmospheric circulation, Atmos. Res., 106, 159-180, 2012.

Esper, J., Cook, E. R., Krusic, P. J., Peters, K., and Schweingruber, F. H.: Tests of the RCS method for preserving low-frequency variability in long tree-ring chronologies, Tree-Ring Res., 59, 81-98, 2003.

Esper, J., Büntgen, U., Luterbacher, J., and Krusic, P.: Testing the hypothesis of post-volcanic missing rings in temperature sensitive dendrochronological data, Dendrochronologia, 13, 216-222, 2013a.

Esper, J., Schneider, L., Krusic, P. J., Luterbacher, J., Büntgen, U., Timonen, M., Sirocko, F., and Zorita, E.: European summer temperature response to annually dated volcanic eruptions over the past nine centuries, B. Volcanol., 75, 736, doi:10.1007/s00445013-0736-z, 2013b.

Esper, J., Großjean, J., Camarero, J. J., García-Cervigón, A. I., Olano, J. M., González-Rouco, J. F., Domínguez-Castro, F., and Büntgen, U.: Atlantic and Mediterranean synoptic drivers of central Spanish juniper growth, Theor. Appl. Climatol., 121, 571, doi:10.1007/s00704-014-1254-4, 2014.

Esper, J., Konter, O., Krusic, P., Saurer, M., Holzkämper, S., and Büntgen, U.: Long-term summer temperature variations in the Pyrenees from detrended stable carbon isotopes, Geochronometria, 42, 53-59, 2015a.

Esper, J., Schneider, L., Smerdon, J. E., Schöne, B. R., and Büntgen, U.: Signals and memory in tree-ring width and density data, Dendrochronologia, 35, 62-72, $2015 \mathrm{~b}$.

Fischer, E. M., Luterbacher, J., Zorita, E., Tett, S. F. B., Casty, C., and Wanner, H.: European climate response to tropical volcanic eruptions over the last half millennium, Geophys. Res. Lett., 34, L05707, doi:10.1029/2006GL027992, 2007.

Frank, D., Esper, J., and Cook, E. R.: On variance adjustments in tree-ring chronology development, in: Tree rings in archaeology, climatology and ecology, edited by: Heinrich, I., Gärtner, H., Monbaron, M., and Schleser, G., TRACE, 4, 56-66, 2006.

Frank, D., Büntgen, U., Böhm, R., Maugeri, M., and Esper, J.: Warmer early instrumental measurements versus colder reconstructed temperatures: shooting at a moving target, Quaternary Sci. Rev., 26, 3298-3310, 2007.

Fritts, H. C.: Tree rings and climate, Academic Press, London, 1976.

Fritts, H. C., Guiot, J., Gordon, G. A., and Schweingruber, F. H.: Methods of calibration, verification, and reconstruction. Methods of Dendrochronology: Applications in the Environmental Sciences, edited by: Cook, E. R. and Kairiukstis, L. A., Dordrecht, Springer Netherlands, 163-217, 1990.

Giorgi, F. and Lionello, P.: Climate change projections for the Mediterranean region, Global Planet. Change, 63, 90-104, 2008.

González-Hidalgo, J. C., Brunetti, M., and de Luis, M.: A new tool for monthly precipitation analysis in Spain: MOPREDAS database (monthly precipitation trends December 1945 November 2005), Int. J. Climatol., 31, 715-731, 2011.

Gonzalez-Hidalgo, J. C., Peña-Angulo, D., Brunetti, M., and Cortesi, N.: MOTEDAS: a new monthly temperature database for mainland Spain and the trend in temperature (1951-2010)m Int. J. Climatol., 35, 4444-4463, doi:10.1002/joc.4298, 2015.

Grove, J. M.: The Little Ice Age, London, Methuen \& Co., Ltd., 498 pp., 1998.

Grudd, H.: Torneträsk tree-ring width and density ad 500-2004: A test of climatic sensitivity and a new 1500-year reconstruction of north Fennoscandian summers, Clim. Dynam., 31, 843-857, 2008.

Guijarro, J. A.: Tendencias de la temperatura en España, in: Fenómenos meteorológicos adversos en España, edited by: García Legaz, C. and Valero, C., AEMET y CCS, Madrid, 2013.

Haigh, J. D. and Cargill, P.: The Sun's Influence on Climate, 1-207, Princeton University Press, Princeton, New Jersey, USA, 2015.

Harris, I., Jones, P. D., Osborn, T. J., and Lister, D. H.: Updated high-resolution grids of monthly climatic observations - the CRU TS3.10 Dataset, Int. J. Climatol., 34, 623-642, 2014.

Hertig, E. and Jacobeit, J.: Assessments of Mediterranean precipitation changes for the 21 st century using statistical downscaling techniques, Int. J. Climatol., 28, 1025-1045, 2008.

Holmes, R. L.: Computer-assisted quality control in tree-ring dating and measurement, Tree-Ring Bull., 43, 69-78, 1983.

Hughes, M. K., Schweingruber, F. H., Cartwright, D., and Kelly, P. M.: July-August temperature at Edinburgh between 1721 and 1975 from tree-ring density and width data, Nature, 308, 341344, 1984.

IPCC: Climate Change 2013: The Physical Science Basis. Contribution of Working Group I to the Fifth Assessment Report of the Intergovernmental Panel on Climate Change, edited by: Stocker, T. F., Qin, D., Plattner, G. K., Tignor, M., Allen, S. K., Boschung, J., Nauels, A., Xia, Y., Bex, V., and Midgley, P. M., Cambridge University Press, Cambridge, United Kingdom and New York, NY, USA, 1535 pp., doi:10.1017/CBO9781107415324, 2013.

Larsson, L. A.: CoRecorder\&CDendro program, Cybis Elektronik \& Data AB, Version 7.6, 2012. 
Lassen, K. and Friis-Christensen, E.: Variability of the solar cycle length during the past five centuries and the apparent association with terrestrial climate, J. Atmos. Sol.-Terr. Phy., 57, 835-845, 1995.

Lean, J., Beer, J., and Bradley, R.: Reconstruction of solar irradiance since 1610: implications for climate change, Geophys. Res. Lett., 22, 3195-3198, 1995.

Lionello, P., Malanotte-Rizzoli, P., Boscolo, R., Alpert, P., Artale, V., Li, L., Luterbacher, J., May, W., Trigo, R., Tsimplis, M., Ulbrich, U., and Xoplaki, E.: The Mediterranean climate: An overview of the main characteristics and issues, Developments in Earth and Environmental Sciences, 4, 1-26, 2006a.

López-Moreno, J. I., El-Kenawy, A., Revuelto, J., Azorín-Molina, C., Morán-Tejeda, E., Lorenzo-Lacruz, J., Zabalza, J., and Vicente-Serrano, S. M.: Observed trends and future projections for winter warm events in the Ebro basin, northeast Iberian Peninsula, Int. J. Climatol., 34, 49-60, 2014.

Luterbacher, J., Rickli, R., Xoplaki, E., Tinguely, C., Beck, C., Pfister, C., and Wanner, H.: The Late Maunder Minimum (16751715) - A key period for studying decadal scale climatic change in Europe, Climatic Change, 49, 441-462, 2001.

Matalas, N. C.: Statistical properties of tree ring data, Hydrolog. Sci. J., 7, 39-47, 1962.

Matskovsky, V. V. and Helama, S.: Testing long-term summer temperature reconstruction based on maximum density chronologies obtained by reanalysis of tree-ring data sets from northernmost Sweden and Finland, Clim. Past, 10, 1473-1487, doi:10.5194/cp10-1473-2014, 2014.

Mencuccini, M., Martínez-Vilalta, J., Vanderklein, D., Hamid, H. A., Korakaki, E., Lee, S., and Michiels, B.: Size-mediated ageing reduces vigour in trees, Ecol. Lett., 8, 1183-1190, 2005.

Mitchell, V. L.: An investigation of certain aspects of tree growth rates in relation to climate in the central Canadian boreal forest. Technical report, 33 pp., Department of Meteorology, University of Wisconsin, 1967.

Pallardy, S. G.: Physiology of Woody Plants, Academic Press, Amsterdam, the Netherlands, 2010.

Panofsky, H. A. and Brier, G. W.: Some applications of statistics to meteorology, University Park, Pennsylvania, 224 pp., 1958.

Pena-Angulo, D., Cortesi, N., Brunetti, M., and González-Hidalgo, J. C.: Spatial variability of maximum and minimum monthly temperature in Spain during 1981-2010 evaluated by correlation decay distance (CDD), Theor. Appl. Climatol., 122, 35-45, 2015.

Pensa, M. and Jalkanen, R.: Variation in needle longevity is related to needle-fascicle production rate in Pinus sylvestris, Tree Physiol., 25, 1265-1271, 2005.

Peñuelas, J.: Plant physiology - a big issue for trees, Nature, 437, 965-966, 2005.
Rinn, F.: TSAPWinTM - Time series analysis and presentation for dendrochronology and related applications, Version 4.69, 2005.

Ruiz, P.: Análisis dendroclimático de Pinus uncinata Ramond en la Sierra Cebollera (Sistema Ibérico), Cuad. Investig. Geográfica, 15, 75-80, 1989.

Sánchez, E., Gallardo, C., Gaertner, M. A., Arribas, A., and Castro, M.: Future climate extreme events in the Mediterranean simulated by a regional climate model: A first approach, Global Planet. Change, 44, 163-180, 2004.

Saz, M. A.: Análisis de la evolución del clima en la mitad septentrional de España desde el siglo XV a partir de series dendroclimáticas, Servicio de Publicaciones de la Universidad de Zaragoza, Zaragoza, 1105 pp., 2003.

Schulman, E.: Dendroclimatic Changes in Semiarid America, Tucson, University of Arizona Press, 142 pp., 1956.

Stokes, M. A. and Smiley, T. L.: An introduction to tree-ring dating, 2nd Edn., The University of Arizona Press, Tucson, 1968.

Tejedor, E., de Luis, M., Cuadrat, J. M., Esper, J., and Saz, M. A.: Tree-ring-based drought reconstruction in the Iberian Range (east of Spain) since 1694, Int. J. Biometeorol., 60, 361-372, 2016.

Tejedor, E., de Luis, M., Saz, M. A., and Cuadrat, J. M.: RW_EW_LW_NESPAIN, figshare, doi:10.6084/m9.figshare.4622059.v2, 2017.

Van der Werf, G. W., Sass-Klaassen, U., and Mohren, G. M. J.: The impact of the 2003 summer drought on the intra-annual growth pattern of beech (Fagus sylvatica L.) and oak (Quercus robur L.) on a dry site in the Netherlands, Dendrochronologia, 25, 103112, 2007.

Vicente-Serrano, S. M. and Cuadrat, J. M.: North Atlantic oscillation control of droughts in north-east Spain: Evaluation since 1600 A.D, Climatic Change, 85, 357-379, 2007.

Wahl, E. R. and Ammann, C. M.: Robustness of the Mann, Bradley, Hughes reconstruction of Northern Hemisphere surface temperatures: examination of criticisms based on the nature and processing of proxy climate evidence, Climatic Change, 85, 33-69, 2007.

Wang, F., Letort, V., Lu, Q., Bai, X., Guo, Y., de Reffye, P., and Li, B.: A Functional and Structural Mongolian Scots Pine (Pinus sylvestris var. mongolica) Model Integrating Architecture, Biomass and Effects of Precipitation, PLoS ONE, 7, e43531, doi:10.1371/journal.pone.0043531, 2012.

Wigley, T. M. L., Briffa, K., and Jones, P. D.: On the average value of correlated time series, with applications in dendroclimatology and hydrometeorology, J. Clim. Appl. Meteorol., 23, 201-213, 1984. 